Meta

Journal des traducteurs

Translators' Journal

\title{
The Semiotic Status of Interlingual Subtitling
}

\section{Panagiotis Sakellariou}

Volume 57, numéro 3, septembre 2012

URI : https://id.erudit.org/iderudit/1017086ar

DOI : https://doi.org/10.7202/1017086ar

Aller au sommaire du numéro

\section{Éditeur(s)}

Les Presses de l’Université de Montréal

ISSN

0026-0452 (imprimé)

1492-1421 (numérique)

Découvrir la revue

Citer cet article

Sakellariou, P. (2012). The Semiotic Status of Interlingual Subtitling. Meta, 57(3), 677-693. https://doi.org/10.7202/1017086ar

\section{Résumé de l'article}

Le présent article traite de la question du statut sémiotique du sous-titrage interlinguistique. Plus spécifiquement, il montre que la conception du sous-titrage comme traduction intersémiotique est théoriquement insoutenable et donc qu'elle ne peut pas fournir la base pour une approche adéquate du caractère particulier de ce type de traduction audiovisuelle. Le statut sémiotique du sous-titrage interlinguistique est essentiellement déterminé par la nature particulière du système audiovisuel. Ainsi, une description sémiotique des processus signifiants audiovisuels permettra d'envisager une conception du statut sémiotique du sous-titrage interlinguistique en termes intertextuels. 


\title{
The Semiotic Status of Interlingual Subtitling
}

\author{
PANAGIOTIS SAKELLARIOU \\ Ionian University, Corfu, Greece \\ northpolex@hotmail.com
}

\section{RÉSUMÉ}

Le présent article traite de la question du statut sémiotique du sous-titrage interlinguistique. Plus spécifiquement, il montre que la conception du sous-titrage comme traduction intersémiotique est théoriquement insoutenable et donc qu'elle ne peut pas fournir la base pour une approche adéquate du caractère particulier de ce type de traduction audiovisuelle. Le statut sémiotique du sous-titrage interlinguistique est essentiellement déterminé par la nature particulière du système audiovisuel. Ainsi, une description sémiotique des processus signifiants audiovisuels permettra d'envisager une conception du statut sémiotique du sous-titrage interlinguistique en termes intertextuels.

\section{ABSTRACT}

This article examines the question of the semiotic status of interlingual subtitling. More specifically, it will be shown that the conception of subtitling as intersemiotic translation is theoretically untenable and therefore cannot provide the basis for an adequate approach to the peculiar character of this type of audiovisual translation. The semiotic status of interlingual subtitling is essentially determined by the particular nature of the audiovisual system. Thus, a semiotic description of the audiovisual signifying processes will be offered that will allow for a conception of the semiotic status of interlingual subtitling in intertextual terms.

\section{MOTS-CLÉS/KEYWORDS}

traduction audiovisuelle, sous-titrage, traduction intersémiotique, système audiovisuel, intertextualité

audiovisual translation, subtitling, intersemiotic translation, audiovisual system, intertextuality

\section{Introduction}

Recent developments in translation studies have given rise to new questions and problems that inevitably lead to the emergence of new research areas. In that way, there occurs a progressive expansion of the discipline's scope that ultimately brings with it the reconceptualisation of translation. Research in audiovisual translation (AVT) is a case in point. To be sure, the main reasons for these developments lie in the respective socioeconomic and intellectual contexts. But the specific ways in which these contexts bear on the scientific study of translation are essentially determined by the dynamics of the discipline's intellectual growth. In what follows, we shall glimpse into a characteristic moment of the current reshaping of translation studies, focusing in particular on the theoretical problems involved in the research on interlingual subtitling. The discussion will start with some preliminary remarks on AVT. It will then proceed to a critical exposition of the concept of interlingual subtitling as intersemiotic translation, in response to which we shall offer an alternative approach in intertextual terms. 


\section{Audiovisual translation: definitions and typologies}

At first glance, audiovisual translation suggests itself as a self-explanatory term referring to a well-defined field. In fact, however, there is no consensus as to what counts as a type of AVT and what does not. A look at some of the most known definitions and typologies reveals the basic divergences in the relevant literature. Karamitroglou (2000: 3) takes AVT as translation of recorded audiovisual material, whereas Cattrysse defines it simply as "the translation of a message into an AV [...] message" (Cattrysse 2001: 2). For Luyken, Herbst et al. (1991: 11), on the other hand, the term denotes generally the process by which a film or television program is made comprehensible to different linguistic communities.

The differences in definitions usually carry over to the proposed typologies, especially when the latter are based on vague or too general definitions. As far as the typologies of AVT are concerned, the various divergences are also due to the variety of the existing and emerging types of audiovisual texts and the different communication requirements posed to the translation process. The divergences among the proposed typologies of AVT range from the most superficial - which are restricted to terminological modifications - to the most essential ones, which stem from a deeper discrepancy in the adopted criteria.

Nevertheless, it should be noted that most of the existing typologies of AVT exhibit a common characteristic: they are based on a fundamental dichotomy between subtitling and re-voicing (Karamitroglou 2000: 4), or subtitling and dubbing (de Linde and Kay 1999: 1). The criterion here refers actually to the material form of the translated discourse. In the case of subtitling, the target text is a written text; in re-voicing (or in dubbing) the target text is a spoken text. The acceptance of such a criterion is not, of course, surprising. The classic distinction between translation and interpretation is based on this very criterion of the material form of both the source text and the target text. On the basis of this dichotomy, various subdivisions have been proposed.

Karamitroglou (2000: 4), for instance, distinguishes the following categories of AVT:
a) subtitling;
b) (lip-sync) dubbing;
c) narration (including voice-over);
d) free commentary.

The categories (b), (c) and (d) form the broader category of re-voicing. For Gambier (1994: 276-277), the field of multilingual transfer in audiovisual communication is subdivided in:
a) subtitling;
b) simultaneous subtitling;
c) dubbing;
d) interpreting;
e) voice-over;
f) narration;
g) commentary;
h) multilingual broadcasting;
i) surtitles or supratitles;
j) simultaneous translation. 
For Luyken, Herbst et al. (1991: 40) AVT comprises:
a) "traditional" subtitling;
b) simultaneous subtitling;
c) lip-sync dubbing;
d) voice-over/narration;
e) free commentary.

The first two types form the category of subtitling, and the last three the category of re-voicing. Finally, de Linde and Kay (1999: 2) distinguish, at a first level, between subtitling and dubbing, and then propose the following list of associated sub-types:
a) simultaneous subtitling;
b) simultaneous interpretation;
c) voice-over;
d) narration;
e) commentary;
f) multilingual diffusion;
g) surtitles;
h) simultaneous translation.

In such typologies one sometimes finds types of translation mingled with various forms of interpretation. The main reason for this might be the fact that factors concerning the use of the products of AVT are foisted into the set of criteria that are taken as a basis for the construction of typologies. These factors are related to the so called "technical aspects" of audiovisual communication, and in that way technical parameters are already present in the proposed typologies of AVT. This of course is unavoidable, given the peculiar nature of audiovisual texts and the impact of the technical parameters of audiovisual communication upon the translation process itself. But often enough these parameters are exploited as typological criteria in a non-systematic way.

The different perspectives adopted in the conception of the notion of AVT are inevitably reflected in the various definitions of subtitling. According to the Dictionary of Translation Studies, subtitling is defined as "the process of providing synchronized captions for film and television dialogue" (Shuttleworth and Cowie 1997: 161). Karamitroglou generalises this notion, defining it as "the translation of spoken (or written) source text of an audiovisual product into a written target text, which is added onto the images of the original product" (Karamitroglou 2000: 5). Gottlieb (2005: 16), for his part, prefers a more analytic definition, according to which subtitling is prepared communication using written language and acting as an additive and synchronous semiotic channel, as part of a transient and polysemiotic text. In contrast with the divergences among the proposed definitions of subtitling, there seems to be a more or less broader consensus as regards the distinction between intralingual and interlingual subtitling (Gottlieb 1998: 247). In intralingual subtitling both the source text and the target text are composed in the same language, whereas in interlingual subtitling the two texts are composed in different languages. In what follows, only interlingual subtitling will concern us, since it is the type of subtitling that by definition pertains to interlingual communication. Therefore, the term $s u b$ titling will henceforth denote "interlingual subtitling." 


\section{The audiovisual system and the conception of subtitling as intersemiotic translation}

In order to elucidate the semiotic status of subtitling, we need to understand the nature of the signifying processes involved in audiovisual communication, and to account for the way in which audiovisual texts are created. An audiovisual text is "a semiotic construct comprising several signifying codes that operate simultaneously in the production of meaning" (Chaume 2004: 16). These signifying codes, however, operate at different levels, depending on the specific material substance of their expression plane. In other words, given that audiovisual technology relies on the combinative use of sound waves and light waves, in each audiovisual text four basic channels can be distinguished:

a) The verbal auditory channel, including dialogue, background voices, and sometimes lyrics;

b) The non-verbal auditory channel, including music, natural sound and sound effects;

c) The verbal visual channel, including superimposed titles and written signs on the screen;

d) The non-verbal auditory channel: picture composition and flow.

(Gottlieb 1998: 245)

Audiovisual translation, like any other type of translation, primarily concerns verbal signs. This means that its focus is on the two verbal channels of the audiovisual text (the verbal auditory channel and the verbal visual channel). In particular, subtitling uses the verbal visual channel for the production of the translated discourse, whereas re-voicing uses the verbal auditory channel. For that reason, it has been claimed that subtitling involves a double transfer, from the oral code to the written code, and from the source language to the target language (Perego 2003: 65). In this case, interlingual subtitling is taken as diagonal translation (Gottlieb 1994: 104-105), in contrast with the standard horizontal translation from written to written, or from spoken to spoken mode.

Before discussing a recently proposed alternative to the standard conception of the semiotic status of subtitling, a few remarks should be made about the use of the term code here. From the 1960s onwards the concept of code has established itself as a key idea in many disciplines, such as linguistics, communication theory, anthropology, and semiotics (see Eco 1984: 164-188; Nöth 1990: 206-220). It has inevitably come to play an equally important role in translation studies, mainly in the form of a "recoding metaphor" about translation (see Delabastita 1993: 2-10). The dominant position of the concept of code in these disciplines in no way implies a unanimous endorsement of a single definition. On the contrary, numerous definitions have as yet appeared displaying various similarities and dissimilarities (see, for example, Cherry 1957/1970: 8; Miller 1951/1963: 7; Thibault 1998: 128; Eco 1976: 37; O' Sullivan, Hartley et al. 1994: 43; Coupland and Jaworski 2001: 170-171; Johansen and Larsen 2002: 7; Danesi 2002: 42). In fact, many of the proposed definitions so far seem to reiterate the concepts of system and rule, although usually no concrete definitions of these concepts are given. Of course there are exceptions to this tendency, and especially in semiotics attempts have been made to provide more elaborate conceptions - for example, Eco's theory of codes (Eco 1976), the bio-semiotic theory of Sebeok and Danesi (2000), or the socio-semiotic approach of Thibault (1998). However, in 
current usage the concept of code is taken more often than not as a "system of signs along with the rules for their use." Straightforward as it may seem, this approach is not unproblematic, but this issue is far beyond the scope of the present article. As regards the application of the concept of code here, suffice to say that our use of the term transcends the aforementioned approach in terms of systems and rules; from our point of view, the emphasis should be put on the social institutions and the existing signifying processes that actually enable us to posit such theoretical constructs as the so-called "semantic codes."

After this necessary digression, we can now return to the question of the semiotic status of subtitling in order to discuss the view that explicitly defines subtitling as intersemiotic translation (Chuang 2006: 372). Jakobson defined intersemiotic translation as "an interpretation of verbal signs by means of signs of nonverbal sign systems" (Jakobson 1971a: 261). Obviously, with this definition in view subtitling could hardly be taken as intersemiotic translation. Even a broader definition, that would encompass any kind of transposition between different semiotic systems (see Jakobson 1971b: 235), would fail to support such a conception. We would have reasons to place subtitling among the various types of intersemiotic translation only if the subtitled bodies of discourse were completely transposed to a different semiotic system. But subtitling is clearly intrasemiotic, because it concerns two different natural languages which, as such, belong to the same semiotic system. This, however, does not mean that we should neglect the crucial role of the various non-linguistic codes involved in the subtitling process. On the contrary, in every audiovisual text meaning emerges through the intricate interplay between the different signifying codes operating in the aforementioned four basic channels. The conception of subtitling as intersemiotic translation presumably aims at highlighting this very fact. Yet, the fusion between linguistic and non-linguistic codes in an audiovisual text does not constitute a necessary and sufficient condition for defining subtitling as intersemiotic translation. Nor does it constitute an extraordinary semiotic phenomenon after all: non-linguistic elements are present essentially in any verbal text. It is therefore obvious that the definition of subtitling as intersemiotic translation is not theoretically justified.

The same conclusion can be drawn from a different - a complementary, as it were - perspective. It is generally acknowledged that audiovisual texts require the use of a set of heterogeneous signifying codes. However, the audiovisual realm is not founded on a mere aggregation of codes belonging to pre-existing semiotic systems, but on the intersection of these systems, and gradually acquires its own sui generis status which cannot be reduced to its semiotic constituents. More specifically, we can distinguish, in every semiotic system, a material substratum, i.e., a material continuum which represents a part of the semiotically unshaped material reality. This continuum is, in Hjelmslev's terms, the expression-purport. For instance, in the case of spoken languages the expression-purport is the range of all possible sounds that can be produced by the human vocal apparatus. Other examples include "the potential of graphic communication, which is used to form systems of writing, or the potential of gestural communication of which sign languages make use" (Nöth 1990: 68). At the content plane, content-purport is a (semiotically) "amorphous thoughtmass" (Hjelmslev 1943: 52). The typical example in this case is the continuum of the colour spectrum. The expression-purport and the content-purport are each time 
formed differently by different systems. Every semiotic system projects on its own substrata its unique form (subdivided into expression-form and content-form, respectively), thus creating its specific content-substance and expression-substance. In Hjelmslev's own words:

[B]y virtue of the content-form and the expression-form, and only by virtue of them, exists respectively the content-substance and the expression-substance, which appear by the form's being projected on to the purport, just as an open net casts its shadows down on an undivided surface. (Hjelmslev 1943: 57)

In Hjelmslev, form is conceived of in terms of abstract distinctions or relations. Substance, on the other hand, is produced by form's acting on the purport. Thus, in a spoken language the range of sounds actually used by its speakers constitutes the expression-substance of that language, whereas the underlying (phonological) system of abstract relations is its expression-form. At the content plane, a typical example is the number distinctions in morphology (Hjelmslev 1943: 53). Many languages share the twofold distinction between singular and plural, but there are also languages with a threefold distinction (singular, plural, and dual), such as the ancient Greek and the Sanskrit. In this case different content-forms imposed on the content-purport produce different morphological forms (categories of content-substance). Hjelmslev's conception of the structuring of semiotic systems can evidently help us elucidate the peculiarities of the audiovisual system. The advent of audiovisual technology created the conditions for the shaping of a part of material reality by a new content-form and a new expression-form. Thus, a new semiotic system emerged with its specific content-substance and expression-substance, as perceived in audiovisual texts. The idiomorphic status of the audiovisual system consists, to some extent, in the fact that its expression-purport partly overlaps with the material substrata of pre-existing semiotic systems. Not surprisingly, then, this new semiotic system evolved through the mutual interaction with other systems. That is why traces of different semiotic codes can be found in every audiovisual work. But if audiovisual texts belong to their specific semiotic system, then subtitling can hardly be considered as intersemiotic translation, since in this case no transposition between different semiotic systems occurs.

\section{The audiovisual signifying codes}

So far we have argued against the conception of subtitling as intersemiotic translation, while acknowledging the fact that it operates in a semiotic space which comprises a series of heterogeneous signifying codes. We have also contended that this semiotic space constitutes a distinct system of signs, and we have shown that its inextricable interrelation with other semiotic systems is primarily due to the specific material conditions of its emergence. Now, we need to move further and take a closer look at the various signifying processes involved in the creation of audiovisual texts. In order to do that, we shall exploit the Hjelmslevian notion of sign-function as it is applied in Eco's model of analysis of semantic units (sememes).

In order to represent the format of the sememe, Eco offers a model of compositional analysis which assigns different types of markers to both functives of a signfunction. ${ }^{1}$ In this model, every sign-vehicle possesses a series of syntactical markers 
and every sememe is formed by a set of semantic markers. The syntactical markers permit the combination of a sign-vehicle with other sign-vehicles (Eco 1976: 92). On the other hand, the semantic markers are the elements that compose the sememe and they are subdivided into four types: a) denotative markers, b) connotative markers, c) contextual selections, and d) circumstantial selections (Eco 1976: 105). Denotative and connotative markers represent respectively the denotations and connotations which compose the sememe. ${ }^{2}$ Contextual and circumstantial selections are selection restrictions which distinguish the different readings of the sememe as encyclopedia item and determine the assignment of a number of denotations and connotations (Eco 1976: 105). More specifically:

Contextual selections record other sememes (or groups of sememes) usually associated with the sememe in question; circumstantial selections record other sign-vehicles (or groups of sign-vehicles) belonging to different semiotic systems, or objects and events taken as ostensive signs, usually occurring along with the sign-vehicle corresponding to the sememe in question; both act as amalgamation switchers. In this way, contextual and circumstantial selections do not require a specific type of instruction, for they are none other than cultural units or expressions, constituting the main nodes of other sememic representations or the elements of the compositional analysis of another sememe. (Eco 1976: 106)

For every analysed sememe, this model yields a tree diagram, a complex network of nodes and paths representing the different readings of the sememe (see Eco 1976: 105). Such diagrams are virtual snapshots of the provisional result of the simultaneous function of different signifying codes. In so far as this model is applicable to every phenomenon of signification, it reveals that every semiotic system is characterised by an incessant amalgamation of various codes. It is therefore misleading to conceive of a semiotic system as a single code (unless such a metaphor implies a network of interrelated codes). So the remarks about the heterogeneous texture of audiovisual texts underscore not only certain aspects of the peculiar nature of the audiovisual system, but also the fact that to a greater or lesser extent every semiotic system is characterised by such heterogeneity. It is precisely for this reason that Jakobson claimed that it is

[...] impossible to analyze exhaustively a single system of signs without constant reference to the general problems of semiotics, and in the context of this new and rapidly developing science the question of the relation between the various systems of signs is one of the fundamental and burning questions. (Jakobson 1971c: 338-339)

In that respect, despite its peculiarities, the audiovisual system is semiotically homologous to other semiotic systems.

The relationship between audiovisual codes and codes belonging to other systems of signs is of a special kind. On the one hand, various denotative and connotative codes enter the audiovisual realm and, in a particular sense, operate in exactly the same way as in every other instance of social life. On the other hand, these codes become the expression plane of audiovisual codes and acquire a certain semiotic role in the creation of audiovisual texts. So, one would be tempted to conclude that there are only connotative audiovisual codes which rely on codes belonging to other semiotic systems. However, this is not the case. As a self-contained system, the audiovisual system comprises its own denotative codes. For example, camera movement and film 
editing can be taken as representing cases of audiovisual denotative codes. And as such, these codes immediately become the basis for a whole series of connotative codes.

The fact that the audiovisual semiotic system does not merely rely on codes belonging to other semiotic systems but also exploits them in its own distinctive ways, thus giving rise to a whole range of new modes of meaning-making processes, has far-reaching consequences as regards its representational and aesthetic aspects. Already in the early days of cinema it was apparent that "the film can not only make a simple record of the events passing before the lens, but that it is in a position to reproduce them upon the screen by special methods, proper only to itself" (Pudovkin 1958: 81). In this sense, neither films nor any other type of audiovisual texts can be taken as mechanical reproductions of reality. After all, in this case the very idea of a mechanical reproduction is problematic. As Arnheim points out, the reproduction of a "perfectly simple object is not a mechanical process but can be set about well or badly," since "even in the simplest photographic reproduction of a perfectly simple object, a feeling of its nature is required which is beyond any mechanical operation" (Arnheim 1959: 296). What holds for photography and cinema holds also for the audiovisual system in general: reality is not just faithfully reflected in audiovisual texts. Rather, the audiovisual system exploits the whole range of its expressive means to create a different kind of reality with its specific time and space, generally known as filmic time and filmic space respectively. In any audiovisual text, then, every element is assigned a meaning and acquires a particular role in respect with this new type of space-time dimension. In short, the audiovisual system builds from the elements of reality a new kind of reality proper only to itself. Any element of social reality can be taken up and be transformed into an audiovisual sign. Langer's statement about filmic art is also true of the audiovisual system in general: indeed, one of the striking characteristics of the audiovisual system is that "it seems to be omnivorous, able to assimilate the most diverse materials and turn them into elements of its own" (Langer 1959: 52).

From the point of view of the sign-function, the interdependence of the heterogeneous codes operating in the audiovisual system can be described in terms of Eco's model of compositional analysis. In an audiovisual text, every meaningful element conveys its particular content not in isolation, but in virtue of the syntagmatic and paradigmatic relations with other elements in the text and in the system of signs as a whole. At the same time, it functions as a contextual and/or circumstantial selection determining some of the readings of other sememes in the text. That is, it acts as a node leading to other sememes and sign-vehicles. Moreover, given the variety of signifying codes that contribute to the meaning of an audiovisual text, it could be said that in this case the circumstantial selections play a crucial role; for it is through this type of selection restrictions that links between the sign-vehicle corresponding to a given sememe and the sign-vehicles belonging to other semiotic systems are established. The audiovisual text is weaved as a meaningful whole in virtue of the creative interplay of such signifying processes.

In other words, what we have here is a ceaseless alternation of semiotic roles. Elements belonging to different semiotic systems interact with each other and become the functives of sign-functions governed by multiple audiovisual codes. However, it should be pointed out that these elements are not deprived of their particular character 
as elements of, say, verbal language, music, etc. They are not dissolved into an audiovisual whole. On the contrary, they are exploitable in the creation of audiovisual texts precisely because they retain their original character as signs belonging to certain semiotic systems.

There is a final remark to be made about the particularity of the audiovisual system. It is true that every semiotic phenomenon occurs in space and time, and thus every system of signs necessarily relies on both dimensions. However, in many cases one dimension takes priority over the other. According to Jakobson, in visual signs

it is the spatial dimension which takes priority, whereas the temporal dimension takes priority in auditory signs. Auditory signs act in a time sequence. Every complex visual sign, for example every painting, presents a simultaneity of various components, whereas the time sequence appears to be the fundamental axis of speech. (Jakobson 1971c: 340)

The essential difference between visual and auditory signs is reflected in the structure of the respective semiotic systems. The systems of auditory signs "present a consistently hierarchised structure" and their signs are "resolvable into ultimate, discrete, rigorously patterned components which, as such, have no existence in nature but are built ad hoc" (Jakobson 1971c: 341). The systems of visual signs, however, lack such hierarchical structures. Since every audiovisual text comprises both visual and auditory signs, it is inevitably constituted as such on the ground of the aforementioned structural discrepancy between these two types of signs.

A considerable part of the discussion so far was mainly concentrated on the idiomorphic nature of the audiovisual system. As we have seen, the crucial peculiarities of the semiotic system in question concern largely two major dimensions: i) the representational and aesthetic aspects of the audiovisual system, and ii) the audiovisual signifying processes. As far as the first dimension is concerned, it was argued that an audiovisual text does not constitute a mechanical reproduction of reality; rather, the audiovisual system provides the semiotic potential that enables the creation of a filmic space and a filmic time, thus giving rise to a new kind of reality. As regards the second dimension, it was pointed out that every audiovisual text is created through the interplay between audiovisual codes and signifying processes belonging to different semiotic systems. It was argued, however, that this fusion of heterogeneous signifying processes does not imply that the various elements in an audiovisual text are deprived of their particular semiotic character. After all, the different types of signs that are used in the creation of an audiovisual work can fulfil their particular semiotic role precisely because they are endowed with a certain semiotic potential. It is this potential, on the other hand, that further enables the emergence of audiovisual signifying processes.

Music, for instance, fulfils its characteristic semiotic roles in the creation of an audiovisual text in virtue of the dialectical relationship between its semiotic potential and certain audiovisual signifying processes. Film music, for example,

[...] can do a variety of things. It can establish setting, specifying a particular time and place; it can fashion a mood and create atmosphere; it can call attention to elements onscreen or offscreen, thus clarifying matters of plot and narrative progression; it can reinforce or foreshadow narrative developments and contribute to the way we respond to them; it can elucidate characters' motivations and help us to know what they are thinking; it can contribute to the creation of emotions, sometimes only dimly realized 
in the images, both for characters to emote and for audiences to feel. Film music can unify a series of images that might seem disconnected on their own and impart a rhythm to their unfolding. (Kalinak 2010: 1)

All these functions are, of course, each time performed in culture-specific ways (Kalinak 2010: 8). Thus there is a variety of semiotic roles that music can fulfil in a film and in any audiovisual work in general, and there is a further variety of ways in which these roles can be fulfilled. It should be emphasised once again that the roles under discussion can be fulfilled - and can provide the basis for the creation of specific codes - precisely because any musical composition in an audiovisual work retains a relative semiotic autonomy. Generalising this point we conclude that the heterogeneous codes operating in the audiovisual realm hold relations of interdependence which can be established as such only insofar as the various signifying processes involved retain a relative semiotic autonomy. Trivial as it may seem, this conclusion deserves special attention here for it reminds us that we should not overemphasise the one pole of this dialectical relationship (the interdependence of the heterogeneous codes) at the expense of losing sight of the other (their particular semiotic character). A failure in recognising the dialectical unity between these two poles may lead to certain misconceptions, such as the notion of subtitling as a type of intersemiotic translation.

\section{Subtitling and Intertextuality}

It is evident from the account given so far that we can still retain the standard or even naïve (as I suspect some scholars would find it) approach to subtitling as a type of interlingual translation without necessarily being caught in the trap of an underestimation of its special semiotic character. But in order to avoid simplistic descriptions, an adequate account of the relationship between an audiovisual work and the verbal texts contained in it is needed. Usually, in a conception of subtitling as a type of interlingual translation this relationship is described in terms of the relationship between a text and its context. It has been argued, however, that this kind of description fails to explain how the different audiovisual modes interact with each other (Chuang 2006: 375). It would be more precise, though, to say that such a failure depends on the specific conception of the notion of context that is each time employed. In any case, there is no need to dwell more on this matter since a different account will be proposed here, not in terms of contextual relations but in terms of intertextuality.

Despite appearances, intertextuality is not a particularly transparent term. Ever since its emergence in the work of Kristeva it has acquired a fairly rich content that bears traces of different discourses and ideologies. It eventually came to cover a wide range of phenomena that had been studied long before Kristeva coined the term. After all, in her work intertextuality first appeared as a translation of the Bakhtinian concept of dialogism (Stam, Burgoyne et al. 1992: 208). It carries then, already from its first appearance, a semantic load that transcends mere reference to the fact that various types of relations hold between different texts. Indeed, in Kristeva intertextuality is indissociably connected with a certain conception of textuality, according to which "any text is constructed as a mosaic of quotations; any text is the absorption and transformation of another. The notion of intertextuality replaces that of inter- 
subjectivity [...]" (Kristeva 1980: 66). A similar conception of textuality can be found in Barthes' definition of text as "a multidimensional space in which a variety of writings, none of them original, blend and clash. The text is a tissue of quotations drawn from the innumerable centres of culture" (Barthes 1977: 146). A famous application of this conception can be found in Barthes' S/Z (Barthes 1970).

Despite the fact that later theories and definitions of intertextuality do not necessarily adopt a purely Kristevan or Barthesian perspective, it can be argued that a cardinal implication of the concept's application in various fields of study is the endorsement of the thesis that texts are not to be conceived of as self-contained structures. Moreover, it is generally acknowledged that intertextuality does not merely concern the influences or the sources of a text, nor does it refer solely to relations holding between verbal texts (Stam 2000: 202-203). These presuppositions do not of course exhaust the semantic potential of the concept under consideration, but they do constitute the necessary basis for the construction of an adequate approach to intertextual phenomena. For the purposes of the present article, we shall take as a point of departure de Beaugrande and Dressler's definition, according to which intertextuality "concerns the factors which make the utilization of one text dependent upon knowledge of one or more previously encountered texts" (de Beaugrande and Dressler 1981: 10). It should be noted that this definition covers both the production and reception of texts (de Beaugrande and Dressler 1981: 182).

A basic feature of intertextual phenomena is that they are not limited to a single semiotic system. In other words, a given text's intertextual relations usually comprise texts belonging to different semiotic systems. This is of particular importance for any account of AVT. Another basic feature of intertextuality concerns the different ways in which a text can be connected with another text. As regards this aspect of intertextuality, de Beaugrande and Dressler speak of the ways in which the participants' intertextual knowledge can be applied in the production and reception of texts. More specifically, they hold that this knowledge "can be applied by a process describable in terms of mediation (the extent to which one feeds one's current beliefs and goals into the model of the communicative situation)" (de Beaugrande and Dressler 1981: 182). According to this view, then,

the greater the expanse of time and of processing activities between the use of the current text and the use of previously encountered texts, the greater the mediation. Extensive mediation is illustrated by the development and use of text types, being classes of texts expected to have certain traits for certain purposes. Mediation is much smaller when people quote from or refer to specific well-known texts, e.g. famous speeches or works of literature. (de Beaugrande and Dressler 1981: 182)

The criterion of mediation implies that all possible ways in which intertextual knowledge can be applied in the production and reception of texts can be represented in a continuum ranging from cases of the most extensive mediation to cases of the slightest mediation. To be sure, such an approach in terms of mediation (in de Beaugrande and Dressler's sense) allows for a quite flexible scheme for classifying different types of intertextual relations. However, we would like to propose here a tentative alternative that would better fit the present exposition. This alternative consists in classifying all possible types of intertextual relations in two major categories: in praesentia intertextual relations and in absentia intertextual relations. Straightforward as it may seem, this classification is not totally unproblematic, and as it will be seen there are 
borderline cases that beset its simple, bipartite structure. As an example, one may consider the category of in praesentia intertextual relations. In what ways the presence of a certain text (or part of it) in another text is to be identified? It seems that a reasonable answer to this question could be adequately given in terms of the text's material manifestation. In quoting, for instance, a certain part of a text is expected to be materially reproduced in another text. Of course, in any such reproduction several alterations may occur, some of them being intended to yield a significant effect (as, for example, when italicising certain words for emphasis). But there are always conventions concerning which kinds of alterations are considered acceptable in order for a reproduction to count as such.

Not surprisingly, there are specific conventions of this kind for each semiotic system because the material particularities of different semiotic systems imply different kinds of reproduction. The appearance of, say, a photograph of Kandindky's Composition VIII in a text does naturally constitute a different kind of reproduction from a quotation from Wittgenstein's Philosophical Investigations. Yet, there seem to be cases that resist a straightforward classification, even if the existence of different kinds of reproduction is acknowledged. In Alexis Damianos' The Charioteer, the director takes the opportunity to represent two paintings of Yannis Tsarouchis in the film, thus paying an implicit and admittedly extraordinary tribute to the Greek painter. Damianos uses all the material at his disposal (scenery, lighting, actors etc.) in order to represent two paintings of Tsarouchis in two distinct scenes (needless to say, it is most likely for these intertextual relations to pass unnoticed even to viewers acquainted with the work of Tsarouchis). Obviously here it is not easy to decide if this is a case of in praesentia or in absentia relations. In a sense, Tsarouchis' paintings are present in the film. Yet they are not reproduced but rather represented, and therefore one might argue that these intertextual links in fact constitute in absentia relations. However, the kind of representation involved here makes it difficult to speak of stricto sensu in absentia intertextual relations. This example is indicative of the fact that even in a rigorously defined dichotomy between in praesentia and in absentia relations borderline cases may occur (it is certainly not incidental that the example in question concerns the audiovisual semiotic system). With this proviso in mind, the categories proposed here can be defined in terms of textual reproduction. More precisely, in the case of an in praesentia intertextual relation there is a conventionally recognisable reproduction of a text (or part of it) in another text. In the case of an in absentia intertextual relation there is only an implicit or explicit reference to a certain text (or part of it). This formulation leaves, undoubtedly, some questions unsettled; therefore, it should rather be taken as a preliminary move towards a more detailed account. Nevertheless, the general classification proposed here will hopefully prove to be adequate for the present discussion.

The conception of intertextuality adopted in this article and the elementary classification of intertextual relations proposed above allow for a quite precise description of the semiotic status of subtitling in intertextual terms. In the previous sections, we have concentrated on the fusion of the heterogeneous codes operating in the audiovisual semiotic system. In this section, the shift in focus from codes to intertextual relations is intended to elucidate the earlier remarks and complete the description offered so far, as regards the ways in which different signifying practices interact with each other in the creation of audiovisual works. As far as the question of the semiotic 
status of subtitling is concerned, the main thesis of the approach outlined here can be stated in the form of the following five basic propositions:

1. In an audiovisual work, a number of different types of texts belonging to various semiotic systems can be identified.

2. In interlingual subtitling, the source text consists of the spoken and written discourse in the audiovisual work; the target text, on the other hand, consists of the subtitles added.

3. Both the source and the target texts are connected with other texts (verbal and nonverbal) through an intricate network of in praesentia and in absentia intertextual relations.

4. The relationship between subtitling and the intertextual network of the audiovisual work is of a dialectical nature. On the one hand, subtitling is in part determined by this intertextual network; on the other hand, the network is partly altered as the result of the subtitling process.

5. From a semiotic point of view, subtitling constitutes a type of interlingual (and not intersemiotic) translation that is considerably determined by in praesentia intertextual relations with non-verbal texts.

Audiovisual products are generally taken as texts. That means that they are generally held to be coherent, meaningful wholes with a certain structure. However, the peculiar nature of the audiovisual system - and, in particular, its capacity for exploiting the potential of different semiotic systems - suggests that audiovisual texts represent a special case of textuality. The fact that a given audiovisual product can be conceived of as a text does not exclude the possibility of identifying in this text a number of other types of texts. On the contrary, the principle of the relative semiotic autonomy of the various types of signs in an audiovisual work entails that each audiovisual text comprises a number of texts belonging to different semiotic systems since audiovisual works are not produced as mere aggregates of dispersed elements but rather are created from elements already formed in meaningful wholes according to rules pertaining to the respective semiotic systems. This, of course, is not to say they are simply collages of pre-existed texts. Every audiovisual text is constructed through the parallel construction and reproduction of different texts, some of them being created precisely in view of their integration in a different textual entity. Among the different texts identified in an audiovisual work certain in praesentia intertextual relations hold - and it could be said that, in a sense, these are the in praesentia intertextual relations par excellence. It is in the network of these intertextual relations that the fusion of heterogeneous codes and signifying practices is each time manifested. In sum, audiovisual works represent a case of multiple texts within a text.

The identification of different types of texts within a single audiovisual work allows for the adequate specification of the source and the target text in subtitling. The discourse in an audiovisual work is organised in certain textual entities. The source text in subtitling consists of these entities, and its relationship with other elements of the audiovisual work is not just of contextual but also of intertextual nature. An audiovisual text does not simply provide a context for the verbal text to be subtitled. It would be more precise to say that this context constitutes a space that comprises various texts interconnected by means of in praesentia intertextual relations. Accordingly, the target text in subtitling consists of the subtitles added to the audiovisual work. Obviously, this addition results, among other things, in creating new links in the intertextual chain of the audiovisual text. 
The intertextual chains of the source and the target text are not limited to the in praesentia intertextual relations with the non-verbal texts contained in the audiovisual work. There are also in praesentia relations with other verbal texts, as well as in absentia relations with verbal and non-verbal texts. Each type of intertextual relations may have a particular significance for subtitling depending on the text to be subtitled, the pair of languages involved, the translational norms that hold in the target language, and so on. In the case of a quotation from the New Testament, for instance, the translational norm in Greece is to cite the respective passage directly from the original text and not to translate it in Modern Greek. This is just one example of the various shifts that can occur in the network of intertextual relations as a result of the translation - or, in this case, the subtitling - process. In an English-speaking film containing quotations from the New Testament, these quotations represent links to the respective English translation of the original text, whereas in the Greek subtitles of that film the intertextual relations established refer to the original text itself. Bearing in mind de Beaugrande and Dressler's definition of intertextuality in terms of the "knowledge of one or more previously encountered texts," one realises the crucial importance of both types of intertextual relations for translation in general. Indeed, it could be argued that intertextuality is one of the major determining factors of the translation process. In the case of subtitling this is perhaps more evident, in part because of the in praesentia intertextual relations among the different types of texts in an audiovisual work. However, in absentia relations are equally important, since not only do they affect the various choices (stylistic, lexicogrammatical, etc.) to be made but, more importantly, through them the shaping of the translator's meaningassignment by different worldviews is substantially affected. Thus, subtitling is necessarily determined by the intertextual networks of audiovisual texts. The other side of the coin is that the subtitling process inevitably affects these intertextual networks. The first and most obvious alteration is caused by the fact that the appearance itself of subtitles on the screen adds immediately an extra link in the chain of the in praesentia intertextual relations among the different types of texts identified in an audiovisual work. Apart from this, various other kinds of alterations occur, such as the one described in the aforementioned example of the quotations from the New Testament.

It should be noted that the dialectical relationship between subtitling and intertextuality does not pertain only to this particular type but essentially characterises translation in general. The peculiarities of subtitling originate mainly from the idiomorphic nature of the intertextual relations established in the audiovisual semiotic system. It is precisely this fact that is highlighted in the fifth proposition above, according to which subtitling is defined as a type of translation that is considerably determined by in praesentia intertextual relations with non-verbal texts. To be sure, this proposition is not intended as a full definition of subtitling. Nor does it ignore or overlook the importance of intertextual relations - both in praesentia and in absentia - with verbal texts. Rather, it should be taken as presenting in a condensed form the main thesis of the semiotic approach offered in this article, according to which subtitling constitutes an intrasemiotic type of translation that is semiotically determined by intersemiotic intertextual relations. Therefore, it should be construed not only in conjunction with the four preceding propositions but, in fact, with the whole of the present exposition concerning the nature of the audiovisual system and the ways in which its peculiarities determine the semiotic status of subtitling. 


\section{Concluding Remarks}

The account outlined above sought to explore part of the potential of the concept of intertextuality for the purpose of elucidating crucial aspects of the semiotic status of interlingual subtitling. The concept of intertextuality was used here in a purely descriptive way and referred to the various intrasemiotic and intersemiotic dependencies between verbal and non-verbal texts. The proposed application of this descriptive concept did not of course aim at just restating major theoretical problems of AVT in fashionable terms. On the contrary, it was intended as a preliminary attempt towards an approach from the perspective of textual interconnectedness that will hopefully shed new light on AVT and its relation to other forms of translation.

\section{NOTES}

1. Eco uses the concept of sign-function in order to redefine the concept of sign in a radical way. In the broad perspective of a general semiotic theory, a sign can be conceived of "as an element of an expression plane conventionally correlated to one (or several) elements of a content plane" (Eco 1976: 48). Signs are constituted as such only when these correlations are recognised by a human society. From the point of view of its correlational aspect, a sign cannot be taken as a physical entity, since the only physical entity one can find in a sign is the element pertaining to its expression plane. On the other hand, signs are not fixed semiotic entities either, but rather a kind of 'meeting ground' for different elements. Therefore, Eco concludes: "Properly speaking there are not signs, but only sign-functions [...] A sign-function is realized when two functives (expression and content) enter into a mutual correlation; the same functive can also enter into another correlation, thus becoming a different functive and therefore giving rise to a new sign-function. Thus signs are the provisional result of coding rules which establish transitory correlations of elements, each of these elements being entitled to enter - under given coded circumstances - into another correlation and thus form a new sign [...] Therefore the classical notion of 'sign' dissolves itself into a highly complex network of changing relationships" (Eco 1976: 49).

2. The redefinition of the concept of sign entails a conception of connotation in terms of interrelated signifying codes. According to Eco, what "constitutes a connotation as such is the connotative code which establishes it; the characteristic of a connotative code is the fact that the further signification conventionally relies on a primary one" (Eco 1976: 55). A connotation is established every time a given signification becomes the expression of a further content. Thus the difference between denotation and connotation is only due to a coding convention; however, "once the convention has been established, the connotation is a stable functive of a sign-function of which the underlying functive is another sign-function" (Eco 1976: 56). This conception of connotation reveals the perpetual fusion of different signifying codes that characterises all semiotic phenomena. Therefore a sign is not just the meeting ground for independent elements, but rather the point of convergence of different denotative and connotative codes which correlate a given expression with a bundle of cultural units.

\section{REFERENCES}

Arnheim, Rudolf (1959): Film as Art. In: Daniel Talbot, ed. Film: An Anthology. New York: Simon and Schuster, 294-323.

BARThes, Roland (1970): S/Z. Paris: Seuil.

Barthes, Roland (1977): Image - Music - Text. (Translated by Stephen Heath) London: Fontana Press.

Cattrysse, Patrick (2001): Multimedia and Translation: Methodological Considerations. In: Yves Gambier and Henrik Gottlieb, eds. (Multi)Media Translation: Concepts, Practices, and Research. Amsterdam/Philadelphia: John Benjamins, 1-12.

Chaume, Frederic (2004): Film Studies and Translation Studies: Two Disciplines at Stake in Audiovisual Translation. Meta. 49(1):12-24. 
Cherry, Colin (1957/1970): On Human Communication. Cambridge: MIT Press.

ChUANG, Ying-Ting (2006): Studying subtitle translation from a multi-modal approach. Babel. 52(4):372-383.

Coupland, Nikolas and Jaworski, Adam (2001): Code. In: Paul Cobley, ed. The Routledge Companion to Semiotics and Linguistics. London/New York: Routledge, 170-172.

DANesi, Marcel (2002): Understanding Media Semiotics. London: Arnold.

Delabastita, Dirk (1993): There's a Double Tongue: An Investigation into the Translation of Shakespeare's Wordplay, with Special Reference to Hamlet. Amsterdam/Atlanta: Rodopi.

De Beaugrande, Robert and Dressler, Wolfgang (1981): Introduction to Text Linguistics. London/New York: Longman.

De Linde, Zoe and Kay, Neil (1999): The Semiotics of Subtitling. Manchester: St. Jerome.

Eco, Umberto (1976): A Theory of Semiotics. Bloomington: Indiana University Press.

Eco, Umberto (1984): Semiotics and the Philosophy of Language. Bloomington: Indiana University Press.

Gambier, Yves (1994): Audiovisual Communication: Typological Detour. In: Cay Dollerup and Annette LindegaArd, eds. Teaching Translation and Interpreting 2: Insights, Aims, Visions. Amsterdam/Philadelphia: John Benjamins, 275-283.

Gotтlieb, Henrik (1994): Subtitling: Diagonal Translation. Perspectives: Studies in Translatology. 2(1):101-121.

GotTlieb, Henrik (1998): Subtitling. In: Mona BAKeR, ed. Routledge Encyclopedia of Translation Studies. London/New York: Routledge, 244-248.

Gotтlieb, Henrik (2005): Texts, Translation and Subtitling: In Theory, and in Denmark. In: Henrik Gotтlieb, ed. Screen Translation. Eight Studies in Subtitling, Dubbing and Voiceover. Copenhagen: University of Copenhagen, 1-40.

Hjelmslev, Louis (1943): Prolegomena to a Theory of Language. (Translated by Francis J. Whitfield) Madison: University of Wisconsin Press.

JAKOBSON, Roman (1971a): On Linguistic Aspects of Translation. In: Stephen Rudy, ed. Selected Writings II. The Hague/Paris: Mouton, 260-266.

JАковson, Roman (1971b): Aphasia as a Linguistic Topic. In: Stephen Rudy, ed. Selected Writings II. The Hague/Paris: Mouton, 229-238.

Jаковson, Roman (1971c): On the Relation between Visual and Auditory Signs. In: Stephen Rudy, ed. Selected Writings II. The Hague/Paris: Mouton, 338-344.

Johansen, Jørgen Dines and Larsen, Svend Erik (2002): Signs in Use. An Introduction to Semiotics. (Translated by Dinda L. GorLéE and John Irons) London/New York: Routledge.

Kalinak, Kathryn (2010): Film Music. A Very Short Introduction. Oxford/New York: Oxford University Press.

Karamitroglou, Fotios (2000): Towards a Methodology for the Investigation of Norms in Audiovisual Translation. Amsterdam/Atlanta: Rodopi.

Kristeva, Julia (1980): Desire in Language: A Semiotic Approach to Literature and Art. (Translated by Thomas Gora, Alice Jardine and Leon Roudiez) New York: Columbia University Press.

Langer, Susanne (1959): A Note on the Film. In: Daniel Talbot, ed. Film: An Anthology. New York: Simon and Schuster, 51-55.

Luyken, Georg-Michael, Herbst, Thomas, Langham-Brown, Jo, et al., eds. (1991): Overcoming Language Barriers in Television: Dubbing and Subtitling for the European Audience. Düsseldorf: The European Institute for the Media.

Miller, George (1951/1963): Language and Communication. New York: McGraw-Hill.

Nöтн, Winfried (1990): Handbook of Semiotics. Bloomington: Indiana University Press.

O'Sullivan, Tim, Hartley, John, Saunders, Darry, et al. (1994): Key Concepts in Communication and Cultural Studies. $2^{\text {nd }}$ ed. London/New York: Routledge.

Perego, Elisa (2003): Evidence of Explicitation in Subtitling: Towards a Categorisation. Across Languages and Cultures. 4(1):63-88. 
Pudovkin, Vsevolod Illarionovich (1958): Film Technique and Film Acting. (Translated by Ivor Montagu) New York: Groove Press.

Sebeok, Thomas and Danesi, Marcel (2000): The Forms of Meaning. Modeling Systems Theory and Semiotic Analysis. Berlin/New York: Mouton de Gruyter.

Shuttleworth, Mark and Cowie, Moira (1997): Dictionary of Translation Studies. Manchester: St. Jerome.

STAM, Robert (2000): Film Theory: An Introduction. Oxford: Blackwell.

Stam, Robert, Burgoyne, Robert and Flitterman-Lewis, Sandy (1992): New Vocabularies in Film Semiotics: Structuralism, Post-structuralism and Beyond. London/New York: Routledge. Thibault, Paul (1998): Code. In: Paul Bouissac, ed. Encyclopedia of Semiotics. Oxford/New York: Oxford University Press, 125-129. 